\title{
Embodied values and ethical principles in somatic dance classes: Considering implicit motor learning
}

Karen Barbour, University of Waikato

\begin{abstract}
Articulating the embodied ways of knowing integral to living in the world, as a dancer, has been a long-term commitment in my own research and practice as both an artist and an educator. Consideration of how somatic practices might be integrated into the institutional structures and knowledge in higher education has led me to investigate underlying values in somatic dance and related movement pedagogies. I have been interested to extend discussion about what is valued in somatic dance education, what movement we choose to teach and for what purposes in higher education, and how we might teach movement ethically and inclusively. An initial discussion about embodied somatic values and ethical principles frames description of somatic dance classes. I then 'massage' particular 'tensions' between different pedagogical approaches including facilitated experiential, discovery-based somatic processes and motor skill learning, to offer some reflections on embodied values and ethical principles for somatic dance.
\end{abstract}

\section{Keywords}

dance

yoga

somatic

embodied

ethical

pedagogy 


\section{Introduction}

For some time I have been interested in the integration of contemporary dance, with yoga and somatic practices in my work in higher education (Barbour 2011, 2013, 2015); a fascination I share with other researchers (cited throughout this article). I agree with Burnidge, who writes that somatic practices support dancers' 'personal discovery and growth, including an emphasis on the development of kinesthetic sense, a focus on the primacy of internal authority, and a fundamental belief in the wholeness of each individual' (2012: 46). The specific context of my work as a dance educator and researcher frames my enquiry. In my university, culturally diverse undergraduate students with varied backgrounds include dance within a number of different degrees. Dance is thus contextualized within education, movement and the arts generally, rather than positioned specifically as training for professional performance. In this broad context, I understand that a 'dance class informed by somatics is not only about constructing our dancing bodies; it is also about developing a more accurate sense of the world we live in' (Fortin et al. 2002: 176; Green 2015; Schaeffer 2015). Thus I offer dance as part of learning about personal well-being and how to live in relationship with others in the world. It is important to me that dance classes allow students to 'experience an embodied sense of vitality and extended capacities for living' (International Somatic Movement Education and Therapy Association [ISMETA] 2011, par. 4).

Critical consideration of my embodied values informs my pedagogical approach to somatic dance (Fraleigh 2015; Stinson 2016). I have long been inspired by critical and feminist pedagogy as articulated in dance research and practice (Burnidge 2012; 
Rouhiainen 2008; Schaeffer 2015; Shapiro 1998). This means that I value understanding how power is enacted in dance contexts; I am concerned about social justice and oppression (including access, participation and voice in dance); and I value identifying hidden curriculums (including gendered behaviour, socialization, docility or agency) (Shapiro 1998; Stinson 2016). Somatic, yoga and dance practices have the potential to connect personal experiences to our communities and the world. As Hanna wrote, a somatic perspective recognizes 'that human beings are bodily beings who can become victims of physical and organic forces, but also that they are equally somatic beings who can change themselves' (1988: 21). Thus, somatic dance aligns with critical and feminist pedagogy within higher education contexts, as I will clarify.

\section{Embodied values in somatic dance}

In relation to my context in higher education, I embody core values from my somatic dance and yoga practices, (noting the influence of Shin Somatics®). Core values of somatic dance that I embody may be expressed as:

- somatic awareness (paying conscious attention to kinesthesia and proprioception, emotions and cognitions)

- movement as well-being (discovering creativity, experiencing movement diversity, integration and rest through intentional moving alone and with others)

- agency and freedom (identifying habit, options and making choices, expressing autonomy as well as relationship through artistic, intentional and aesthetic movement) 
- caring and belonging (practicing self-care and self-healing, demonstrating empathy and compassion, sharing and collaborating with others, leading and teaching to express relationships with others).

These core values are expressed through my embodied ways of knowing (Barbour 2011; Csordas 1993; Dragon 2015; Schaeffer 2015). Taking a critical and feminist perspective, I care about what and how we teach, and that we support students to develop embodied knowledge. I do not wish to make uncritical assumptions about the learning and impact of somatic dance classes.

While the focus of this article is on my considerations as an educator, ongoing research has engaged regular discussions and contributions from the dancers I work with (Barbour 2011, 2013), as well as discussion with other educators (Barbour 2015). Further research to understand dancers' experiences is important in pedagogical practice, although my focus here is on illustrating ethical pedagogical principles that arise from embodying core somatic dance values.

\section{Embodied ethical principles in dance classes}

In developing embodied ethical principles for teaching somatic dance, I referred to many sources including feminist ethics of care (Noddings 2003), philosophical and spiritual teachings of yoga (Desikachar 1995; Farhi 2006; Iyengar 1994, 2001), guidelines of the International Somatic Movement Education and Therapy Association (ISMETA) (2011), somatic practices (Bannerman 2010; Batson and Schwartz 2007; Batson and Wilson 2014; Brodie and Lobel 2012; Dragon 2015; Eddy 2009; Feldenkrais 1972/1990; Hanna 1988; Hartley 1989; Olsen 2014; Schaeffer 2015), culturally responsive pedagogies (Gay 
2000; Shor 1992) and dance pedagogy (Erkert 2003; Kassing and Jay 2003; Shapiro 1998). A key source for understanding the integration of dance, somatics and yoga has been Shin Somatics ${ }^{\circledR}$ (Fraleigh 2009, 2015). The following embodied ethical principles frame my pedagogy and specific practices.

- Meet where we are

- Move and learn together

- Celebrate the wealth of embodied knowledge we bring

- Invite us all to extend our existing embodied knowledge

- Foster relationships and dialogue

- Affirm and respect personal, family and cultural identities

- Do no harm.

In order to illustrate these principles within the context of somatic dance, I provide a description of class activities below that also demonstrates my pedagogy. I note that there are overlapping relationships between the values of somatic dance as I embody them and these embodied ethical principles. For example, value of somatic awareness is encapsulated in the ethical principles of meeting where we are, in moving and learning together, and in both celebrating and extending existing embodied knowledge. Sondra Fraleigh's comments express these intentions as she encourages starting where you are, learning as you do and building capacity as you go $(2009,2015)$. So these ethical principles arise out of somatic dance values and interrelate in overlapping ways, as highlighted in descriptions below.

My somatic dance classes loosely follow the structure outlined by Fortin et al. (2002) in their pivotal article on the effect of somatic education on contemporary dance. Incorporating warm up, awareness through movement activities, transition to standing, 
dance technique and combinations with my own adaptations and nuances, I anticipate that I share much with other somatic dance educators (Erkert 2003). However, I describe my dance classes in order to further discussion about how we actually practice somatic dance, drawing on discovery-based, inclusive and culturally responsive pedagogies, as well as traditional instructional approaches and critical feminist pedagogies.

\section{Somatic dance classes}

\section{Dance class warm up}

Dance classes normally begin with social greetings and an invitation to begin simple personal warm ups. As students move through the studio, they are prompted to add favorite movements that increase core body temperature and heart rate with light cardio activities, and mobilizing the joints through a normal functional range of motion. Importantly, the ethical principle to meet the students where they are at - literally travelling to class and bringing familiar movement - is embodied and the wealth of embodied knowledge they bring is affirmed.

\section{Dance class awareness through movement activities}

Following this short warm up, activities involve awareness of moving drawing on Shin Somatics ${ }^{\circledR}$ (Fraleigh 2009, 2015), rather than Feldenkrais Method as Fortin et al. did (2002). Pausing in familiar dance parallel and turned out standing positions, as well as yoga standing position with one leg rotated slightly in and the other outwards (as though moving into standing poses such as trikonasana [triangle pose]) (Barbour 2013). Shifting weight in these standing positions reveals familiarity as well as unfamiliar asymmetric rotation of the legs in the hip sockets. Movement awareness activities in 
Shin Somatics ${ }^{\circledR}$ then move from 'land to water' backwards ontogenetically from vertically aligned human engagement with the world on land, retrograding through development patterns to the floor and to watery embryonic beginnings (Fraleigh 2009, 2015). These simple movements are supported by teacher moving with students, rather than instructing and demonstrating, or task modeling (Fortin et al. 2002). Analogies, images and simple prompts drawing on sensory experience support a structured improvisation with developmental movements.

Once on the floor, somatic activities and dance patterns are integrated into floor sequences with constructive rest often functioning as the centre position from which movement begins and returns (Alexander 1932/1985). Sequences incorporate navel radiation, homologous, homolateral and contralateral patterning, head to tail connection, star rolls (or X rolls), 'lazy lizard', experimentation with low tone and hyper tone, moving from centre and more (Alexander 1932/1985; Brook 2000; Cohen 2008; Erkert 2003; Feldenkrais 1972/1990; Fraleigh 2009; Hanna 1988; Hartley 1989; Kirk 2014; Long 2006; Schaeffer 2015). Rest is included, acknowledging 'the somatic notion of balance between rest and action as a fundamental pedagogical strategy, and its implications for technique and creative practice, as well as its effect on general wellbeing and personal authority' (Batson and Schwartz 2007: 48). Floor activities continue into deeper sequences with easy transitions (Erkert 2003), and referencing yoga vinyasa (flowing phrases) rather than āsana (poses). This somatic work offers opportunities for students to extend and deepen their existing embodied knowledge.

Throughout, the movement is embodied while verbal prompts are offered so that teacher and dancers move together. As teacher/facilitator, moving allows me to teach from my own somatic awareness. Specific methods to facilitate movement awareness include, 
1) highlighting different ways to achieve the task, 2) comparing sensations of different movement initiations in task execution, 3) directing attention to the sensation of movement in task execution, 4) describing the movement skeletally while looking for precise sensations, 5) repeating movement to obtain a clearer sensation, 6) using tactile feedback with a partner, 7) self questioning. (Fortin et al. 2002: 166)

Moving together becomes part of the important discovery learning process as well as the basis of studio relationships (Barbour 2011). This practice invites students into a gentle, improvisational, sensory engagement. No one is overtly watching them, they are affirmed as embodied knowers and they are enabled to choose how they participate and rest. Somatic dance values are embodied through a range of pedagogical approaches and the ethical principles to meet where we are, celebrate and extend dancers' embodied knowledge, while and moving and learning together, are evident.

While I personally embrace somatic dance, I also recognize that I cannot ethically only teach in this way because to do so might deprive students of the journey back to everyday interaction with others in their communities and the world at large. I agree with Fortin et al. (2002) as they argue that enhanced proprioception through somatic dance does not have to only focus on inward experience, and that

somatics might create a path toward social consciousness... It has the potential to change the ways we see the world around us, starting with the most private: ourselves. A new perception of our body-soma can result in a new position from which to view the world. (Fortin et al. 2002: 175) 
Dancers need opportunities to discover connections and to transfer their learning in somatic dance to everyday life in order to experience agency and freedom. As a teacher, I aim to affirm and respect students' own personal, family and cultural identities (Barbour 2011), and supporting them to connect somatic dance knowledge to what is known and valued in their families and communities, is very important. The pedagogical aim is for transfer of embodied knowledge so that students' everyday interactions as well as their dancing expressions are extended by their capacity to move with a deeper somatic mode of attention.

\section{Dance class transition to standing}

Transition to standing involves completing the cycle of 'land to water yoga' and returning through developmental movement to standing (Fraleigh 2009, 2015). Activities support a reassembling of verticality in the body with the invitation to transfer floor sensori-motor experiences into standing work (Cohen 2008; Erkert 2003; Fortin et al. 2002). In the return to standing, the intent is to support experiences of alignment, stability and balance, as well as adaptability, flexibility and retaining awareness of movement. The preparatory work of experiencing asymmetrical hip rotation and movements on the floor, support transition into standing āsana and vinyasa. I approach the integration of yoga movement with a sense of curiosity and approximation, using verbs of permission with students (Fraleigh 2014). Prompts might also include selfquestioning about alignment and emotional state (Fortin et al. 2002).

For some dancers, somatic awareness may evoke psychological and emotional responses, such as power or joy, but also including despair and frustration (Bennett 2002; Cardinal 2014; Dolan 2007). For some, recognition of sensation of any sort may prompt both thrilling life-changing insights and highlight social insecurities. While the 
transfer of sensori-motor learning and awareness is a valuable intention, some students may not yet have the capacity to maintain sensory awareness lightly and engage in moving with others. Necessarily, this transfer of learning is an ongoing process and may likely continue beyond higher education experiences (Barbour 2013).

The overall intent in this section of class is 'for students to conceptualize and organize the new knowledge being acquired, and for teachers to help students recognize this knowledge as transferrable, along with the potential situations for transfer to be identified' (Fortin et al. 2002: 161). Specific practices that support a confident return for students to standing and everyday life, as well as transfer of somatic awareness, are: optimal standing alignment, bringing the eyes to the horizon and simple expansive movement.

One approach to optimal standing alignment is expressed through yoga tdāsana (mountain pose) (Iyengar 2001; Long 2006). Within the act of standing, sensory awareness is activated of joint position, balance and stability to support a functional alignment and integrity in an efficient, well-balanced posture that expresses natural spinal curves (Feldenkrais 1972/1990; Long 2006). In optimal standing alignment, 'the skeletal structure should counteract the pull of gravity, leaving the muscles free for movement' (Feldenkrais 1972/1990; Long 2006). In somatic dance

Postural imbalance sometimes occurs when dancers strive too willfully to meet external aesthetic demands. Because deep involuntary muscles are not accessible through volition, more efforts to adapt to someone else's image might not necessarily result in more efficient moving unless accompanied by new perceptual input. (Fortin et al. 2002: 172-73) 
Transferring sensory awareness from floor into standing may allow recognition of proprioceptive information that supports efficiency and ease in dancing.

Another specific practice to support a confident return for students to standing and a transfer of somatic awareness is Fraleigh's practice of bringing the eyes to the horizon (2009). This practice also supports optimal standing alignment, balancing the head on the spine, opening the sternum and encouraging the gaze to literally move off the floor and into the space. Accompanied by an invitation to make eye contact with other people and to greet others while walking with eyes on the horizon is a simple practice to support optimal alignment and interaction with others. While cultural differences may arise, especially with students who are socialized not to look directly as teachers or elders as a sign of respect, seeing out to the horizon can nevertheless support students to lift their gaze off the floor.

A third practice is to open outwards, literally opening both arms up and out to each side diagonal while easily extending the spine and neck, thus opening the sternum and throat area, and allowing the gaze to move upwards on the diagonal. This type of movement has been described in psychological research on body language and reveals that people feel more powerful when performing expansive movement. Carney et al. (2010, 2015: 662) commented that specifically 'holding an expansive yoga-style pose for two to three minutes significantly increases blood-serum levels of testosterone and decreases blood-serum levels of cortisol' (Minvaleev et al. 2004). Thus, there is potential for integrated dance, yoga and somatic classes to intentionally use expansive movement phrases to reduce stress and increase a sense of confidence, agency and empowerment in dancers. These practices are informed by ethical principles to expand dancers' embodied knowledge, to move and learn together and to foster relationships. 
These three simple practices combined into a movement phrase may support students in the transition to standing and to social interaction. This is important because even while deeply engaged in internal sensing, dancers remain in relationship with the world; a world full of movement and sensation to delight and interact with. Somatic awareness can support openness to the breathing of the world while supporting openness to cellular breathing (Cohen 2008; Fraleigh 2009; Hartley 1989). However, time, commitment and practice is definitely required of dancers in order to cultivate this kind of openness.

\section{Dance class technique and combinations}

Many dancers are both genuinely enthusiastic about, and have also been conditioned through dance technique training to expect more energetic expansive contemporary dance movement. A pedagogical shift occurs in relation to embodied ethical principles and a transformation in pedagogy is important (Barbour 2015). A range of dance activities reference familiar movements, and thus align with the ethical principles of meeting students, celebrating existing embodied knowledge, and extending existing embodied knowledge.

Familiar movement patterns include foot articulations, battements, swings and expansive phrases that travel across the studio with different skill foci. These closed or discrete perceptual-motor skills are combined into movement phrases with expressive qualities. Kassing and Jay state that the teacher typically 'demonstrates the exercise, step, or movement, verbalizing the cues and instructions using action words or dance terminology without, and then with, the music to make the movement-language connection for the students' in the verbal-cognitive stage of learning (2003: 47; Schmidt and Wrisberg 2000; Smith 2007). Demonstrations 'display some of the essential features 
of the skill' and utilize observational learning (Schmidt and Wrisberg 2000: 211); and guidance procedures provide temporary assistance through physical guidance and touch. These kinds of direct instructional teaching methods are very common, particularly in traditional dance pedagogy (Shapiro 1998). Reflecting on traditional dance pedagogy prompts consideration of the value of a more student-centred, inclusive and discovery-based approach, particularly for students who are not training for professional performance and are not required to replicate movement exactly. Motor skill learning theory aligns with traditional pedagogy and helps teachers understand how dancers progress through cognitive and motor stages of learning towards autonomous movement performance (Erkert 2003; Fortin et al. 2002; Kassing and Jay 2003; Puretz 1998; Schmidt and Wrisberg 2000; Smith 2007).

However, underlying values and ethical principles in somatic dance do not align well with traditional dance pedagogy and an entirely instructional approach towards motor skill learning. Instead, somatic dance aligns more with student-centred and inclusive, feminist and critical pedagogies and with the ethical principles of celebrating each student for their unique existing embodied knowledges and offering learning that extends students as they move and learn together. Somatic dance teachers need to be sensitive to individual student needs, develop student-centred aproaches and use a range of pedagogical approaches.

However, dance students may still desire some teacher demonstrations of movement sequences and much dance knowledge is usefully shared through embodiment. Demonstrations are particularly valuable to share movement quality and with complex high-speed skills (Erkert 2003; Schmidt and Wrisberg 2000). Thus, teaching dance combinations may involve an initial demonstrate to provide a 'sketch' of the movement and articulate 'the goal of understanding one's personal way of executing 
the combinations' (Fortin et al. 2002: 160). As Catherine Schaeffer writes, this 'opens options in "owning" the material as they shade it with their own preferences' (2015: 81), observe each other and demonstrate their own interpretations. The intention is that students become able '1) to find and rely on their own sensations, 2) to define learning goals for themselves, 3) to learn from observing peers' movement, and to 4) solve movement problems' (Fortin et al. 2002: 163). There are opportunities to reflect within even the faster-paced sections of class and students are supported to demonstrate their own interpretations. In somatic dance, the point is that teachers should limit demonstrations and 'allow discovery in the learning process' (Schaeffer 2015: 83).

In everyday life, dancers have learned motor skills through direct instruction (such as learning to drive), and they have also learned through discovery and improvisation (such as cooking or walking around the local park). Much can be learned from research on motor skill learning that supports understandings of dance learning and highlights the benefits of varying pedagogical approaches.

\section{Dance class embodied ways of knowing}

A further challenge is to foster embodied ways of knowing through transferring both the movement learning and the learning process from earlier sections of class. Between the early and middle sections of dance classes the pedagogical approach shifted. However, students' learning in somatic dance can be shifted back towards the aim for empowerment in everyday life by supporting students to identify what is most personally useful and to practice exercising their agency and freedom. Consequently, the practice is offered to students to choose experiences from the class to embody and investigate in a five to ten minutes activity. This practice may appeal to some students as 
an open improvisation, and others may need structure and prompts (Erkert 2003; Schaeffer 2015).

Embodied ways of knowing draw on insights developed through somatic awareness using proprioceptive and kinaesthetic knowledge, awareness of which is deepened through somatic dance. Philosophically, embodied ways of knowing are epistemological strategies: ways of knowing in which knowledge is constructed, contextual and embodied (Barbour 2011). We synthesize the knowledge gained from somatic awareness with knowledge gained through other strategies; experience ourselves as constructing and creating knowledge (supporting agency and freedom); and reconcile this knowledge in personally meaningful ways as we live out our lives (movement as well-being), in relationship to others and the world (caring and belonging) (Barbour 2011).

Experimental and experiential research provides evidence for and assists in understanding epistemological strategies (Batson and Wilson 2014). Studies of proprioception reveal how we sense our posture, balance and bodily movement in space. Through deepening our bodily awareness we recognize touch, temperature and pressure, skin stretch, muscle effort and fatigue, joint position, information from internal organs, balance, voluntary and involuntary reflexive movements and much more (Batson and Wilson 2014; Brewer 1998; Eilan et al. 1998; Rouhiainen 2008). This sensory knowledge supports synthesizing and reconciling knowledge in meaningful ways, reflecting the values of somatic dance in embodied ways of knowing.

\section{Cool down and closure}

A slower practice to return dancers to everyday activity may reference specific āsana and somatic sensori-motor activities explored earlier in class. Reflection time, 
potentially including discussion of personal experiences and feedback, and a closing ritual, completes the somatic dance class.

The detailed description above of somatic dance classes and the pedagogical approaches utilized to illustrate embodied ethical principles is only one approach but provides the impetus for further reflections. Arising from these reflections are particular tensions to massage in the following discussion.

\section{Reflections on learning movement}

There remains source of tension in investigating pedagogy in this context. When dancers rely on explicit motor learning, they direct their conscious attention to sensory motor activity in the process of modifying known movement: they utilize somatic awareness. In this process, dancers require access to working memory to remember rules and concepts, to test options and to store information gained by trial and error (Kassing and Jay 2003; Puretz 1998). The declarative knowledge that is encoded during such learning can easily be used for conscious control of movement, according to the theory of reinvestment (Masters 1992; Masters and Maxwell 2008). Explicit motor learning theory and the assumptions about this kind of learning are embedded in dance pedagogy (Kassing and Jay 2003). Somatic dance teachers also refer to such detailed explicit motor knowledge when encouraging repeated movement patterns, in using references to the skeleton to assist understanding and using touch to provide feedback (Fortin et al. 2002). Sometimes this also leads to complicated and lengthy attempts to articulate procedural knowledge verbally.

Interestingly, Rich Masters and co-researchers, suggest that a great deal of focus on explicit motor skill learning (or re-learning), on the sensation of movement, and on remembering declarative information (instructions and cues), may actually hinder 
learning and performance of motor skills (Masters 1992; Masters and Maxwell 2008; Masters and Poolton 2012). In the explicit motor skill learning process, dancers are forced to 'reinvest' in known movement patterns, which can cause autonomous movements to be undone. The consequence is that there is often 'a drop in performance when [performers are] provoked to consciously attend to their movements by pressure manipulations or self-focus instructions...' (Masters and Maxwell 2008: 162). So particularly when under pressure in learning, dancers may experience a breakdown of their ability to perform known movements: they may feel like beginners in the cognitive stage of learning again. For example, even a simple plié (knee bend) may suddenly become more difficult to perform if the dancer is asked to focus specifically on alignment in the lower spine or is coping with a knee injury. And the consequences of changing knee bends may really interfere with students' performance of movement. Further, these researchers argued that

attention to the effects of one's movements on the environment (an external focus of attention) is preferable to an internal focus on attention on one's movements, [as] an internal focus of attention encourages conscious control of the movements, which constrains or inhibits automatic control mechanisms. (Masters and Maxwell 2008: 162)

Thus, an identifiable tension within my pedagogical approach in somatic dance is that deepening somatic awareness and fostering an internal focus of attention in these dance classes, may also be creating harm to students as they may experience a drop in performance of even simple dance skills. 
Subsequently, Masters and colleagues (Masters 1992; Masters and Maxwell 2008; Masters and Poolton 2012) have argued that implicit motor learning strategies may be more valuable than explicit motor learning. Implicit motor learning involves acquiring movement skills without explicit conscious processes (Masters and Poolton 2012). Masters and colleagues (Masters 1992; Masters and Maxwell 2008; Masters and Poolton 2012) have argued that implicit learning is very valuable for learning ontogenetic movement skills requiring specialized coordination, such as dance movement. Furthermore, 'findings imply that implicit motor learners do not need to progress through an initial cognitive stage of learning' (Masters and Poolton 2012: 69). Drawing on this research, I speculate about what this offers somatic dance and what the implications for embodied ethical pedagogies might be.

Ethically, if I am mindful that somatic dance learning may break down dancers' capacity to perform previously autonomous movement (at least temporarily), I need to consider carefully how my pedagogy might support dancers in retaining their capacity and confidence. Even if only temporary, such a change in performance capacity may be perceived by dancers as harmful, especially while they also need to continue to perform in other dance contexts. Emotional harm, such as frustration in performing movement in class, and harm in lower achievement in assessment activities, may also be experienced. Dancers may experience a loss of confidence in performing known roles within community, church or family settings. Rather than continue with the assumption that somatic dance and deepening somatic awareness is inherently good for dancers, I wish to delve into this issue. Perhaps utilizing implicit motor learning strategies may reduce or even avoid reinvestment and bypass the cognitive stage of motor learning. Perhaps implicit motor learning may thus avoid the drop in performance of movement resulting 
from reinvestment. Perhaps an external focus of attention may also be valuable in some dance learning activities.

Application of these ideas in practical dance classes is an ongoing research endeavour and collecting student responses to implicit motor learning strategies is a future step. However, to share my initial research, I outline two implicit motor learning methods.

\section{Implicit motor learning methods for somatic dance}

Applying implicit motor learning theory in somatic dance classes may assist in developing embodied ethical pedagogies, support students in their embodied ways of knowing and confident performance in dance. There are two initial observations I draw from implicit motor learning research (Masters and Maxwell 2008; Masters and Poolton 2012). The first observation is that the research suggests it is valuable to offer opportunities to learn without errors.

\section{Errorless learning}

The value of errorless or error-reduced learning approaches is that immediate success and incremental change removes the need for dancers to engage their working memory. Such approaches may prevent dancers actively testing hypotheses about the best way to move (which normally occurs during trial and error). Errorless learning means that learners achieve success consistently which allows dancers to retain the stable performance of their known autonomous dance movements, such as a plié, and subtly experience incremental and gradual modifications to movement (Masters and Maxwell 2008; Masters and Poolton 2012). Dancers begin with the embodied knowledge they 
bring and enhance their skills through successful incremental change, recalling Fraleigh's encouragement to build capacity as you go $(2009,2015)$.

In somatic dance, much of the early warm up and awareness through movement activities on the floor utilize simple developmental movement, repeated with deeper somatic awareness. Incremental errorless learning is more likely when complex new motor skill learning is not the focus. In the transition to standing, by paying attention to alignment at the knee joint and experimenting with subtle change while standing and walking, dancers can begin a gentle process of incremental change in alignment over time (recalling Alexander's notions of inhibition and re-patterning [1932/1985]). I would suggest that dance classes can potentially make more use of incremental errorless learning and thus celebrate the wealth of embodied knowledge each dancer brings, building on what they know already while also extending existing embodied knowledge and supporting students' capacity and confidence in performing.

\section{Analogy learning}

A second method of implicit motor learning is to offer analogies, allowing dancers to infer understandings without consciously accessing and thinking through underlying rules and concepts (Masters and Maxwell 2008; Masters and Poolton 2012). Analogy learning enables dancers to grasp complex relationships without having to access procedural information and test hypotheses explicitly. Comparing two un-alike things may enable understanding of movement in a simpler way. Again, somatic dance and yoga includes many effective examples of analogy learning that can potentially be used to greater effect. As an example, a simple analogy is that our legs are like stretchy elastic bands when we plié (knee bend). This analogy can support fluidity through the range of motion in knee flexion and extension, avoiding the tendency to 'lock' the knee joint at 
full extension or hyperextension. Another more sophisticated analogy is to imagine that our fascia is like an exact, delicate lace outline of our entire body and that we might approach dancing through space with the freedom of this delicate structure (Mandoline Whittlesey, February 2015, workshop communication). This analogy can support sensory awareness to shift away from dwelling on muscles, joints and bones, offering a positive alternative when students are working with injury or needing to embody complex movement holistically.

I suggest that analogy learning may also support dancers in moving and learning together, particularly in classes in which students may have very different sets of rules and experiences that frame their moving. Analogies that bring attention to an external focus may particularly support implicit motor learning. Thus the development of shared analogies from the everyday lives of specific groups of students may support new experiences in moving and learning together.

\section{Reflections and conclusions about embodied values and ethical principles in}

\section{somatic dance}

It seems to me that implicit motor learning offers much to teachers of somatic dance. In particular, errorless learning and analogies are implicit learning methods that are already part of somatic practices and that we might draw on more. Recalling somatic dance values and embodied ethical principles, implicit learning strategies such as these align well.

With an intention to meet students where they are in their everyday life and in their dance learning, the knowledge dancers' bring may be celebrated and personal, family and cultural identities may be affirmed and respected, while at the same time building incrementally on known movement and avoiding a drop in movement 
performance as a result of reinvestment. In maintaining dancers' capacities to perform valued movement, errorless and analogy-based learning strategies are useful. In celebrating the wealth of embodied knowledge dancers bring with them, their existing movement may also be extended and support offered to integrate new experiences as personally relevant and as embodied through improvisation, expressing agency and freedom. In moving and learning together, dancers may be prompted to recognize the importance of other students' nuanced movement qualities and expression alongside teacher offerings, and together may develop analogies inclusive of students from different cultural and movement backgrounds, expressing caring and belonging. Further, in fostering relationships and dialogue, embodied learning in the social environment of the dance studio may reference previous motor skill learning experiences as well as prompting discussion, feedback and reflection. Enhancing confident performance and expression while supporting a deepening somatic awareness and a practice of movement as well-being may be possible. These embodied ethical principles reflect core values as I have embodied them in somatic dance: somatic awareness, movement as well-being, empowerment and freedom, caring and belonging.

In somatic dance classes, enhanced use of relevant methods of implicit motor learning can support ethical pedagogies. Most importantly, implicit motor learning avoids doing harm, in that known dance movements valued by students in their personal, family and cultural contexts are not destabilized and the students' ability to perform with confidence is maintained. These reflections leave me with a little less tension and more ease in my commitment to embodied ethical principles in pedagogy. In future research I seek student responses to these pedagogical practices. I hope to stimulate more discussion of specific pedagogical practice and of core somatic values as we embody them in unique and nuanced ways in higher education. 


\section{Acknowledgements}

Thanks to Sondra Fraleigh and Rich Masters for feedback, to the blind reviewers for their insights, and to the dancers with whom I learn in somatic dance classes.

\section{References}

Alexander, F. M. (1932/1985), The Use of the Self, London: Orion Books.

Bannerman, H. (2010), 'A question of somatics - the search for a common framework for twenty-first-century contemporary dance pedagogy', Journal of Dance and Somatic Practices, 2:1, pp. 5-19.

Barbour, K. N. (2011), Dancing Across the Page: Narrative and Embodied ways of Knowing, Bristol, UK: Intellect Books.

__ (2013), 'Cultivating embodied ways of knowing: Integrating contemporary dance and yoga practice in tertiary education', in Close Encounters: Contemporary dance didactics: Explorations in Theory and Practice, Stockholm, Sweden: University of Dance and Circus, pp. 105-16.

_ (2015), 'Yoga teachers' insights in working with dancers: Pedagogical approaches in transformation', in C. F. Stock and P. Germain-Thomas (eds), Contemporising the Past: Envisaging the Future, Refereed Proceedings of the 2014 World Dance Alliance Global Summit, Angers, France, 6-11 July, World Dance Alliance and Ausdance, http://ausdance.org.au/publications/details/contemporising-the- 
past-envisaging-the-future Accessed 18 October 2016.

Batson, G. and Schwartz, Ray E. (2007), 'Revisting the value of somatic education in dance training through an inquiry into practice schedules', Journal of Dance Education, 7:2, pp. 47-56.

Batson, G. and Wilson, M. (2014), Body and Mind in Motion: Dance and Neuroscience in Conversation, Chicago and Bristol, UK: Intellect Books.

Bennett, B. (2002), Emotional Yoga: How the Body can Heal the Mind, Sydney and Auckland: Bantam Books.

Brewer, B. (1998), 'Bodily awareness and the self', in J. Bermudez, A. Marcel and N. Eilan (eds), The Body and the Self, Cambridge, MA: MIT Press, pp. 291-310.

Brodie, J. and Lobel, E. E. (2012), Dance and Somatics: Mind-Body Principles of Teaching and Performance, Jefferson, NC: Macfarlane and Co.

Brook, A. (2000), Contact Improvisation and Body-Mind Centering: A Manual for Teaching and Learning Movement, Layayette, CO: Body-Mind.Net.

Burnidge, A. (2012), 'Somatics in the dance studio: Embodying feminist/democratic pedagogy', Journal of Dance Education, 12:2, pp. 37-47.

Cardinal, M. K. (2014), 'SPICE22: Wellness dimensions applied to dance with advice for 
teachers', Journal of Physical Education, Recreation and Dance, 85:3, pp. 3-7.

Carney, D. R., Cuddy, A. J. C. and Yap, A. J. (2010), 'Power posing: Brief nonverbal displays affect neuroendocrine levels and risk tolerance', Psychological Science, 21:10, pp. $1363-68$.

_ (2015), 'Review and summary of research on the embodied effects of expansive (vs. contractive) nonverbal displays', Psychological Science, 26:5, pp. 657-63.

Cohen, B.B. (2008), Sensing, Feeling and Action: The Experiential Anatomy of Body-Mind Centering ${ }^{\circledR}, 2$ nd ed., Northampton, MA: Contact Editions.

Csordas, T. J. (1993), 'Somatic modes of attention', Cultural Anthropology, 8:2, pp. 13556.

Desikachar, T. K. V. (1995), The Heart of Yoga: Developing a Personal Practice, Rochester, VT: Inner Traditions International.

Dolan, M. (2007), 'A new transformation in higher education: Benefits of yoga and meditation', International Forum of Teaching and Studies, 3:1, pp. 31-36.

Dragon, D. A. (2015), 'Creating cultures of teaching and learning: Conveying dance and somatic education pedagogy', Journal of Dance Education, 15: 1, pp. 25-32.

Eddy, M. (2009), 'A brief history of somatic practices and dance: Historical development 
of the field of somatic education and its relationship to dance', Journal of Dance and Somatic Practices, 1:1, pp. 5-27.

Eilan, N., Marcel, A. and Bermudez, J. (eds) (1998), 'Self-consciouness and the body: An interdisciplinary introduction', in The Body and the Self, Cambridge, MA: MIT Press, pp. 1-28.

Erkert, J. (2003), Harnessing the Wind: The Art of Teaching Modern Dance, Champaign, IL: Human Kinetics.

Farhi, D. (2006), Teaching Yoga: Exploring the Teacher-Student Relationship, Berkeley, CA: Rodmell Press.

Feldenkrais, M. (1972/1990), Awareness through Movement, New York: Harper One.

Fortin, S., Long, W. and Lord, M. (2002), 'Three voices: Researching how somatic education informs contemporary dance technique classes', Research in Dance Education, 3:2, pp. 155-79.

Fraleigh, S. (2009), Land to Water Yoga: Shin Somatics® Moving Way, Bloomington, IN: iUniverse Inc.

_ (2014), 'Permission and the making of consciousness', in A. Williamson, G. Batson, S. Whatley and R. Weber (eds), Dance, Somatics and Spiritualities: Contemporary Sacred Narratives, Bristol, UK and Chicago: Intellect Books, pp. 239-60. 
(ed.) (2015), Moving Consciously: Somatic Transformations through Dance, Yoga and Touch, Urbana, Chicago and Springfield, IL: University of Illinois Press.

Gay, G. (2000), Culturally Responsive Teaching: Theory, Research and Practice, New York: Teachers College Press.

Green, J. (2015), 'Moving in, out, through, and beyond the tensions between experience and social construction in somatic theory', Journal of Dance and Somatic Practices, 7:1, pp. 7-19.

Hanna, T. (1988), Somatics: Reawakening the Mind's Control of Movement, Flexibility, and Health, Cambridge, MA: Da Capo Press.

Hartley, L. (1989), Wisdom of the Body Moving: An Introduction to Body-Mind Centering, Berkeley, CA: North Atlantic Books.

International Somatic Movement Education and Therapy Association (ISMETA) (2011), 'ISMETA scope of practice', http://www.ismeta.org/. Accessed 20 February 2016.

Iyengar, B. K. S. (1994), Light on Yoga: Yoga Dipika, Rev. ed., New York: Schocken Books.

__ (2001), Light on Yoga: Yoga Dipika, New York: Harper Thorsons.

Kassing, G. and Jay, D. M. (2003), Dance Teaching Methods and Curriculum Design: 
Comprehensive K-12 Dance Education, Champaign, IL: Human Kinetics.

Kirk, J. (2014), 'Experiencing our anatomy: Incorporating human biology into dance class via imagery, imagination, and somatics', Journal of Dance Education, 14:2, pp. 59-66.

Long, R. (2006), The Key Muscles of Yoga: Your Guide to Functional Anatomy in Yoga, 3rd ed., Baldwinsville, New York: Bandha Yoga Publications.

Masters, R. S. W. (1992), 'Knowledge, knerves and know-how: The role of explicit versus implicit knowledge in the breakdown of a complex motor skill under pressure', British Journal of Psychology, 83:3, pp. 343-58.

Masters, R. S. W. and Maxwell, J. (2008), 'The theory of reinvestment', International Review of Sport and Exercise Psychology, 1:2, pp. 160-83.

Masters, R. S. W. and Poolton, J. M. (2012), 'Advances in implicit motor leaning', in N. J. Hodges and A. M. Williams (eds), Skill Acquisition in Sport, 2nd ed., London and New York: Routledge, pp. 59-75.

Minvaleev, R. S., Nozdrachev, A. D., Kir'yanova, V. V. and Ivanov, A. I. (2004), 'Postural influences on the hormone level in healthy subjects: I. The cobra posture and steroid hormones', Human Physiology, 30:4, pp. 452-56.

Noddings, N. (2003), Caring: A Feminine Approach to Ethics and Moral Education, 
Berkeley, CA: University of California Press.

Olsen, A. (2002), Body and Earth: An Experiential Guide, Middeltown, CT: Wesleyan University Press.

(2014), The Place of Dance: A Somatic Guide to Dancing and Dance Making, Middeltown, CT: Wesleyan University Press.

Puretz, S. (1998), 'Psychomotor research and the dance teacher', in P. Clarkson and M. Skrinar (eds), Science of Dance Training, Champaign, IL: Human Kinetics, pp. 279287.

Rouhiainen, L. (2008), 'Somatic dance education as a means of cultivating ethically embodied subjects', Research in Dance Education, 9:3, pp. 241-56.

Schaeffer, C. (2015), 'Living Shin', in S. Fraleigh (ed.), Moving Consciously: Somatic Transformations through Dance, Yoga and Touch, Urbana, Chicago and Springfield, IL: University of Illinois Press, pp. 75-92.

Schmidt, R. A. and Wrisberg, C. A. (2000), Motor Learning and Performance: A ProblemBased Learning Approach, 2nd ed., Champaign, IL: Human Kinetics.

Shapiro, S. B. (ed.) (1998), Dance, Power and Difference: Critical and Feminist Perspectives on Dance Education, Champaign, IL: Human Kinetics. 
Shor, I. (1992), Empowering Education: Critical Teaching for Social Change, Chicago: University of Chicago Press.

Smith, B. R. (2007), 'Body, mind and spirit? Towards an analysis of the practice of yoga', Body and Society, 13:2, pp. 25-46.

Stinson, S. W. (2016), Embodied Curriculum Theory and Research in Arts Education: A Dance Scholar's Search for Meaning, Switzerland: Springer.

\section{Contributor details}

Dr Karen Barbour is Associate Professor in Te Oranga School of Human Development and Movement Studies at the University of Waikato, New Zealand. Her research focuses on embodied ways of knowing, particularly feminist choreographic practices in dance theatre, site-specific, digital dance and pedagogical movement contexts. Her book publications include Dancing Across the Page: Narrative and Embodied ways of Knowing (2011) and Ethnographic Worldviews: Transformations and Social Justice (Rinehart, Barbour and Pope, 2014). Karen is editor of the journal Dance Research Aotearoa, presents regularly at international dance conferences and has published her writing in a range books and journals.

\section{Contact:}

The University of Waikato, Private Bag 3105, Hamilton 3240, New Zealand.

E-mail: karenb@waikato.ac.nz 